Original Article

\title{
Age-related changes in muscle elasticity around the shoulder joint in young male baseball players: A prospective longitudinal study
}

\author{
Eri Kobayashi a, b, Hiromi Matsumoto ${ }^{c}$, Ikuta Hayashi ${ }^{\text {d }}$, Mari Osaki a , Hiroshi Hagino a, e, * \\ ${ }^{a}$ Rehabilitation Division, Tottori University Hospital, Nishicho 36-1, Yonago, Tottori 683-8504, Japan \\ b School of Health Science, Tottori University Graduate School of Medical Science, Nishicho 86, Yonago, Tottori 683-8503, Japan \\ ${ }^{c}$ Department of Rehabilitation, Faculty of Health Science and Technology, Kawasaki University of Medical Welfare, Matsushima 288, Kurashiki, Okayama \\ 701-0193, Japan \\ d Department of Orthopedic Surgery, Faculty of Medicine, Tottori University, Nishicho 36-1, Yonago, Tottori 683-8504, Japan \\ e School of Health Science, Faculty of Medicine, Tottori University, Nishicho 86, Yonago, Tottori 683-8503, Japan
}

\section{A R T I C L E I N F O}

\section{Article history:}

Received 2 April 2019

Received in revised form

16 June 2019

Accepted 24 June 2019

Available online $\mathrm{xxx}$

\begin{abstract}
A B S T R A C T
Background: Longitudinal changes of elasticity in the muscle tissues around the shoulder joint during the growth period have not been assessed using shear wave elastography.

Methods: This study enrolled male students aged 13-18 years who played baseball or rubber baseball as an extra-curricular activity during junior high or high school or on a baseball team outside of school. The exclusion criterion was a history of surgery for athletic injury. One hundred and twenty-one boys were included in the study. The elasticity of the superior part of the trapezius, the supraspinatus, and the infraspinatus were measured by ultrasound. The shear elastic modulus (SEM), which is the ratio of the strain ratio (SR) in the acoustic coupler to the SR of each muscle, was calculated as a representative value. Six months after the baseline assessment, subjects were evaluated regarding any newly developed pain in the joint of the throwing shoulder, and categorized into either the non-pain group or the pain group. Results: Although all muscle SEMs tended to increase in both the throwing and non-throwing shoulders, no significant difference was observed in the prevalence of shoulder joint pain between ages $(\mathrm{p}=0.541)$. The results of a binominal logistic regression analysis, adjusted for age, body mass index, playing position in baseball, frequency of baseball practice, shoulder range of motion, and muscle strength showed that a decrease in SEM values of the supraspinatus was a risk factor for the development of new pain (odds ratio: 0.056; 95\% confidence interval 0.011-0.299; $\mathrm{p}=0.001$ ).

Conclusions: The elasticity of muscle tissues around the throwing shoulder increased with age, and low tissue elasticity of the supraspinatus of the throwing shoulder was a factor that triggered pain during throwing motions.
\end{abstract}

(C) 2019 The Japanese Orthopaedic Association. Published by Elsevier B.V. All rights reserved.

\section{Introduction}

Muscle stiffness is caused by physiological stimuli such as muscle fatigue and exercise stress on the muscles [1], and constitutes important information when suspecting or diagnosing muscle injury. Furthermore, while it is known that an increase in muscle stiffness may compromise athletic performance [2,3], muscle stiffness must be evaluated based on subjective palpation by a

\footnotetext{
* Corresponding author. School of Health Science, Faculty of Medicine, Tottori University, Nishicho 86, Yonago, Tottori 683-8503, Japan. Fax: +81 859386308

E-mail addresses: kobaeri0501@yahoo.co.jp (E. Kobayashi), h.matsumoto0612@ mw.kawasaki-m.ac.jp (H. Matsumoto), hagino@tottori-u.ac.jp (H. Hagino).
}

trainer or a player's complaints, and there is no standard objective and scientific evaluation technique.

In attempting to objectively measure muscle stiffness, evaluation of the muscle-tendon complex may be performed. This involves assessing the degree of force required to displace a muscle [2] or using a tissue hardness meter. However, these methods have several drawbacks; for example, they measure the thickness of the subcutaneous fat as well as the muscle, and they are unable to evaluate deep muscles. Recently, however, it has become possible to use ultrasonography to evaluate tissue elasticity (defined based on the strain ratio: SR), which represents how stiff the muscle is compared to subcutaneous fat. In particular, the SR obtained by shear wave elastography is clearly distinguished from 
conventional "muscle stiffness" that is defined as the resistance of muscle to vertical pressure [4].

Evaluation of the SR may predict future athletic injuries. For example, stiffness and unbalanced muscle tissues around the shoulder joint lead to repetition of an inappropriate throwing motion, which places an excessive load on the shoulder during throwing motions in baseball and frequently causes muscle injury [5]. A previous Japanese study found that $13.6-15.9 \%$ of youth and junior high school baseball players reported episodes of shoulder pain [6,7]. Since children in their growth years demonstrate faster bone growth than muscle and tendon growth, and their muscles and tendons remain immature even though their body type is already established, they are vulnerable to muscle injury due to excessive exercise stress. A previous study reported that in children who were still growing, the presence of epiphysial lines, decreased flexibility of the lower extremities and body trunk, excessive repetition of throwing motions, and busy game schedules were risk factors for the development of throwing-related injuries [2]. However, no reports have examined the elasticity of muscle tissues around the shoulder and its relationship with age and the development of throwing-related injuries or pain.

In this study, therefore, we longitudinally investigated whether changes in the elasticity of muscle tissues around the shoulder joint were associated with the incidence of shoulder pain in school-age baseball players, by measuring the SR of these muscles using shear wave elastography.

\section{Subjects and methods}

\subsection{Subjects}

This study enrolled male students aged $13-18$ years who played baseball or rubber baseball as an extra-curricular activity during junior high or high school or on a baseball team outside of school. Students were excluded if they had a history of surgery for athletic injury.

One hundred and twenty-one boys (mean age $16.5 \pm 2.8$ years; mean height $164.5 \pm 8.6 \mathrm{~cm}$; mean weight $57.5 \pm 11.4 \mathrm{~kg}$ ) were included in the study. Nineteen subjects were 13 years old, 18 were 14 years old, 14 were 15 years old, 23 were 16 years old, 25 were 17 years old, and 22 were 18 years old. All participants and their guardians provided written informed assent and consent, and this research was approved by the local ethics committee of the authors' affiliated institutions.

\subsection{Study design}

This study was a prospective, longitudinal, observational study.

\subsection{Baseline assessment}

\subsubsection{Characteristics}

The subjects were asked about their age, playing position in baseball, and frequency of baseball practice (number/week) during the past 3 months, and their height was measured. For subjects who did not have a regular playing position, we asked what position they played most frequently in games. They were also asked to respond either "yes" or "no" to a question asking if they had pain in the joint of the throwing shoulder during baseball practices or games. We defined shoulder pain as pain around the shoulder while throwing a ball or pitching during exercise and in games.

\subsubsection{Body composition}

A body composition analyzer MC-780A (Tanita, Tokyo, Japan) was used to measure body weight, body mass index (BMI), percent body fat, body fat amount, lean body mass, and muscle mass. Subjects stepped onto the analyzer and remained standing for approximately $30 \mathrm{~s}$. The measurement was performed before they perspired during baseball practice, and they wore light clothing without shoes or socks.

\subsubsection{Shoulder range of motion}

The University of Tokyo-type goniometer (TAKASE MED, Tokyo, Japan) was used to measure joint range of motion. External and internal rotation angles were measured by a single examiner. Subjects were placed in a supine position with the forearm in a neutral position during the measurement of shoulder external and internal rotation angles in the second position (shoulder $90^{\circ}$ abduction). These angles were measured using the vertical line on the frontal plane through the elbow as the stationary axis and the ulna as the movement axis.

\subsubsection{Muscle strength of knee and shoulder}

A single examiner measured the bilateral knee extension strength and the external rotation strength of both shoulders in a $90^{\circ}$ abduction position using a hand-held dynamometer ( $\mu$-tas F-1; ANIMA Co., Ltd., Tokyo, Japan). Beginning at $90^{\circ}$ knee flexion in a sitting position without back support, subjects performed approximately $5 \mathrm{~s}$ of maximum voluntary isometric knee extension. To measure muscle strength, the examiner applied the hand-held dynamometer to the anterior surface of the distal leg. Subjects repeated the exercise three times, and rested for a minute or more between measurements. The external rotation strength of the shoulder was measured in a pronated position, with the shoulder joint in a $90^{\circ}$ abduction position, the elbow joint flexed at $90^{\circ}$ and the forearm in a pronated position. As with the knee measurements, the subjects performed approximately $5 \mathrm{~s}$ of maximum voluntary isometric shoulder external rotations, and the examiner applied the dynamometer to the dorsal surface of the distal forearm. Subjects performed this exercise three times, and rested for a minute or more between measurements. The measurement results were corrected for body weight, and the mean value of the three measurements was used as a representative value.

\subsubsection{Measurement of the $S R$}

The HI VISION Avius (Hitachi Aloka Medical, Tokyo, Japan) ultrasound imaging system was used to measure the SR. The shear wave elastography function of the system was used with a linear probe (EUP-L75) (frequency 18-5 Hz; viewing field width $38 \mathrm{~mm}$ ) attached to an acoustic coupler (EZU-TECPL1; Hitachi Aloka Medical, Tokyo, Japan). The acoustic coupler was made of an elastomer resin and had a constant elastic modulus of $22.6 \mathrm{kPa}$. For quantitative analysis, the SEM, which is the ratio between the SR in the acoustic coupler and the SR of each muscle (muscle/coupler), was calculated as a representative value. Smaller SEM values indicate greater elasticity, and larger SEM values indicate greater inflexibility [8-10]. Minor pressure applied with the probe was confirmed on the strain graph on the ultrasound imaging system. The measurement was considered appropriate only when the rhythmical compression-relaxation cycle was within the range of -0.7 to 0.7 . Based on a previous study, the region of interest for SR analysis was set to $4 \mathrm{~mm}$ (vertical) $\times 30 \mathrm{~mm}$ (horizontal) for the acoustic coupler and $18 \mathrm{~mm}$ (vertical) $\times 40 \mathrm{~mm}$ (horizontal) for the target muscle. To ensure that clear images were obtained, an appropriate amount of gel was applied between the probe and the acoustic coupler as well as between the acoustic coupler and the skin.

The SR measurements of the fibers of the superior part of the trapezius, and of the supraspinatus and infraspinatus muscles of both shoulders were performed with each subject in a sitting position without back support, with their shoulder joint in a lowered position 
and with their hands on their lap. For imaging the superior part of the trapezius, the transducer was placed at a point $2 \mathrm{~cm}$ lateral to the midpoint between the spinous process of $\mathrm{C} 7$ and the lateral edge of the acromion. For imaging the supraspinatus, the transducer was placed at the midpoint of the line connecting the acromion to the inner corner of the scapula. Finally, for imaging the infraspinatus, the transducer was placed at the midpoint of the line from the acromion to the lower corner and from the acromion to the inner corner of the infraspinatus [11]. The measurement of the teres minor muscle was performed with the shoulder joint flexed at $90^{\circ}$, the elbow joint flexed at $90^{\circ}$ and the forearm in a neutral position, and the subject used a cushion to maintain good posture and to prevent muscle contraction during the measurement. For imaging the teres minor muscle, the transducer was placed on outside of the midpoint of the line connecting the acromion and the lower corner of the scapula [11].

The assessment of muscle elasticity in our study was performed in the resting state, at 9 to 10 o'clock in the morning before stretching and exercise, to exclude measurement bias [12,13]. In addition, we performed measurements three times and defined the average as the representative value. During ultrasonography, the probe was placed parallel to the direction of the muscle fibers [14]. A 1-min break was taken between the measurement of each site. One examiner who was skilled at elastography conducted the measurements in this study. The reproducibility of SR measurements was evaluated in seven healthy adult male subjects (mean age: $32.5 \pm 8.2$ years; range: $28-44$ years) who had no orthopedic disorders. In this reproducibility evaluation, SR measurements were repeated three times per subject, with a 5-min break between each measurement.

\subsection{Follow-up assessment}

At follow-up examination 6 months after the baseline assessment, we determined whether subjects had any newly developed pain in the joint of the throwing shoulder. A numerical rating scale (NRS) was used, and subjects with a score of 0 were categorized into the non-pain group, while those with a score of 1 or higher were categorized into the pain group.

\subsection{Statistical analysis}

The joint range of motion, muscle strength, and SEM values were analyzed for the throwing and non-throwing shoulders.

To evaluate the reproducibility of SEM values, intraclass correlation coefficients (ICCs) $(1,3)$ and the coefficient of variation (CV) were calculated. The difference in the prevalence of shoulder joint pain between ages was tested by the chi-square test. Furthermore, the Jonckheere-Terpstra test was used to identify trends of changes in SEM values of each muscle according to age. To compare the SEM values of each muscle between the throwing and non-throwing shoulders for each age, the unpaired t-test was used. To evaluate factors associated with the development of pain in the throwing shoulder 6 months after the baseline assessment, binominal logistic regression analysis was performed using the presence or absence of new pain as a dependent variable and the SR value of each muscle as an independent variable. All data were analyzed using SPSS statistical software (Version 24 for Windows; IBM Co., Ltd. Tokyo).

\section{Results}

\subsection{Evaluation of the reproducibility of SEM}

ICCs $(1,3)$ were $0.927,0.786,0.788$, and 0.914 for the supraspinatus, infraspinatus, teres minor muscles, and fibers of the superior part of the trapezius, respectively. CVs were $0.67,0.71,0.66$, and 0.70 for the supraspinatus, infraspinatus, teres minor muscle, and fibers of the superior part of the trapezius, respectively. All values indicated intermediate to high levels of reproducibility.

\subsection{Characteristics}

Table 1 shows data on subject height, body weight, BMI, percent body fat, body fat amount, lean body mass, muscle mass, frequency of baseball practice, range of external rotation of the throwing and non-throwing shoulders, isometric external rotation strength of the throwing and non-throwing shoulders, and knee extension strength on the throwing and non-throwing sides. Ninety-four subjects threw right-handed and 27 threw left-handed. Twenty subjects were pitchers, 6 were catchers, 44 were infielders, 34 were outfielders, and 17 played as a pitcher or catcher in addition to another position.

Fig. 1 shows the SEM values of each muscle by age. The results of the trend test (p-trend) using the Jonckheere-Terpstra test showed that the SEM values of the fibers of the superior part of the trapezius ( $p<0.001, p<0.001$ ), and the values of the supraspinatus ( $\mathrm{p}<0.001, \mathrm{p}<0.001)$, infraspinatus $(\mathrm{p}<0.001, \mathrm{p}<0.001)$, and teres minor muscles $(\mathrm{p}<0.001, \mathrm{p}<0.001)$ of the throwing and nonthrowing shoulders tended to increase with age. For most of the muscles in both shoulders, the SEM values increased in a step-like

Table 1

Anthropometric and muscle strength data in each age group.

\begin{tabular}{|c|c|c|c|c|c|c|c|}
\hline & \multirow{2}{*}{$\frac{\text { Total }}{(N=121)}$} & \multirow{2}{*}{$\frac{13 \text { years }}{(n=19)}$} & \multirow{2}{*}{$\frac{14 \text { years }}{(n=18)}$} & \multirow{2}{*}{$\frac{15 \text { years }}{(n=14)}$} & \multirow{2}{*}{$\frac{16 \text { years }}{(n=23)}$} & \multirow{2}{*}{$\frac{17 \text { years }}{(n=25)}$} & \multirow{2}{*}{$\frac{18 \text { years }}{(n=22)}$} \\
\hline & & & & & & & \\
\hline Height (cm) & $164.5 \pm 8.6$ & $161.0 \pm 12.0$ & $166.6 \pm 2.3$ & $163.3 \pm 6.6$ & $166.5 \pm 9.3$ & $164.7 \pm 7.5$ & $164.6 \pm 8.1$ \\
\hline Body weight $(\mathrm{kg})$ & $57.5 \pm 11.4$ & $53.2 \pm 11.9$ & $61.7 \pm 8.2$ & $55.3 \pm 12.1$ & $60.0 \pm 12.1$ & $57.3 \pm 11.2$ & $56.6 \pm 11.7$ \\
\hline Body mass index $\left(\mathrm{kg} / \mathrm{m}^{2}\right)$ & $21.0 \pm 2.9$ & $20.2 \pm 2.2$ & $22.1 \pm 3.0$ & $20.5 \pm 3.0$ & $21.4 \pm 2.9$ & $20.9 \pm 2.9$ & $20.7 \pm 3.3$ \\
\hline Body fat (\%) & $17.8 \pm 5.1$ & $18.2 \pm 5.1$ & $20.1 \pm 8.0$ & $19.0 \pm 4.4$ & $16.8 \pm 4.2$ & $16.3 \pm 3.6$ & $17.4 \pm 4.8$ \\
\hline Body fat mass (kg) & $10.4 \pm 4.5$ & $10.6 \pm 4.8$ & $12.6 \pm 6.8$ & $11.4 \pm 4.0$ & $9.6 \pm 3.7$ & $9.1 \pm 3.1$ & $10.0 \pm 4.3$ \\
\hline Lean body mass (kg) & $46.0 \pm 5.2$ & $44.7 \pm 7.7$ & $47.4 \pm 2.5$ & $46.9 \pm 5.8$ & $46.1 \pm 4.5$ & $45.8 \pm 4.2$ & $45.3 \pm 5.9$ \\
\hline Muscle mass (kg) & $43.5 \pm 4.9$ & $42.4 \pm 7.2$ & $44.8 \pm 2.4$ & $44.4 \pm 5.5$ & $43.7 \pm 4.2$ & $43.4 \pm 3.9$ & $42.9 \pm 5.6$ \\
\hline Practice frequency (number/week) & $3.4 \pm 1.9$ & $2.5 \pm 1.2$ & $2.4 \pm 1.2$ & $3.2 \pm 1.8$ & $4.5 \pm 2.3$ & $3.5 \pm 2.1$ & $3.6 \pm 1.9$ \\
\hline \multicolumn{8}{|l|}{ Range of motion of shoulder } \\
\hline Internal rotation in throwing shoulder $\left(^{\circ}\right)$ & $73.7 \pm 12.3$ & $75.2 \pm 9.4$ & $74.7 \pm 8.3$ & $72.8 \pm 9.1$ & $74.1 \pm 9.7$ & $72.0 \pm 15.8$ & $73.6 \pm 17.2$ \\
\hline Internal rotation in non-throwing shoulder $\left({ }^{\circ}\right)$ & $74.0 \pm 21.6$ & $73.9 \pm 28.7$ & $77.5 \pm 11.4$ & $81.43 \pm 14.2$ & $72.8 \pm 21.9$ & $69.2 \pm 23.9$ & $73.1 \pm 22.3$ \\
\hline External rotation in throwing shoulder $\left(^{\circ}\right)$ & $103.5 \pm 10.1$ & $105.5 \pm 5.2$ & $106.3 \pm 13.3$ & $102.1 \pm 9.5$ & $101.8 \pm 9.9$ & $102.2 \pm 10.6$ & $102.2 \pm 10.6$ \\
\hline External rotation in non-throwing shoulder $\left({ }^{\circ}\right)$ & $95.0 \pm 12.5$ & $91.3 \pm 10.7$ & $95.7 \pm 8.2$ & $91.9 \pm 15.3$ & $96.0 \pm 12.4$ & $95.8 \pm 12.8$ & $98.1 \pm 11.8$ \\
\hline \multicolumn{8}{|l|}{ Muscle strength } \\
\hline External rotation strength in throwing shoulder (kgf/kg) & $0.11 \pm 0.04$ & $0.11 \pm 0.05$ & $0.10 \pm 0.01$ & $0.15 \pm 0.07$ & $0.10 \pm 0.03$ & $0.10 \pm 0.03$ & $0.09 \pm 0.04$ \\
\hline External rotation strength in non-throwing shoulder $(\mathrm{kgf} / \mathrm{kg})$ & $0.10 \pm 0.05$ & $0.09 \pm 0.04$ & $0.11 \pm 0.04$ & $0.15 \pm 0.09$ & $0.08 \pm 0.03$ & $0.10 \pm 0.04$ & $0.09 \pm 0.04$ \\
\hline Knee extension strength in throwing side $(\mathrm{kgf} / \mathrm{kg})$ & $0.60 \pm 0.12$ & $0.60 \pm 0.10$ & $0.63 \pm 0.09$ & $0.66 \pm 0.15$ & $0.57 \pm 0.13$ & $0.59 \pm 0.13$ & $0.58 \pm 0.10$ \\
\hline Knee extension strength in non-throwing side ( $\mathrm{kgf} / \mathrm{kg})$ & $0.61 \pm 0.14$ & $0.64 \pm 0.13$ & $0.59 \pm 0.10$ & $0.66 \pm 0.16$ & $0.58 \pm 0.14$ & $0.60 \pm 0.16$ & $0.60 \pm 0.11$ \\
\hline
\end{tabular}

Data are mean \pm SD. 
a

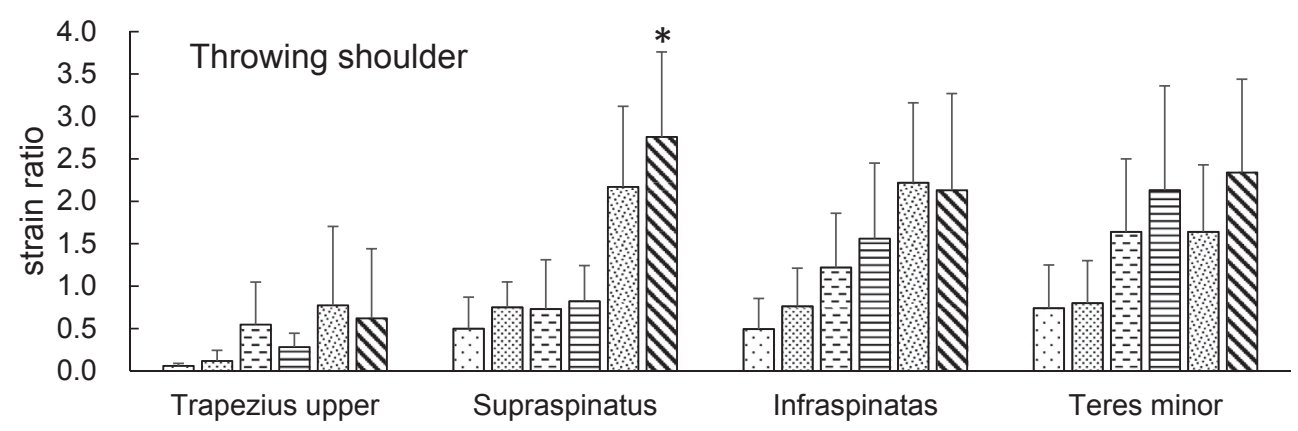

b

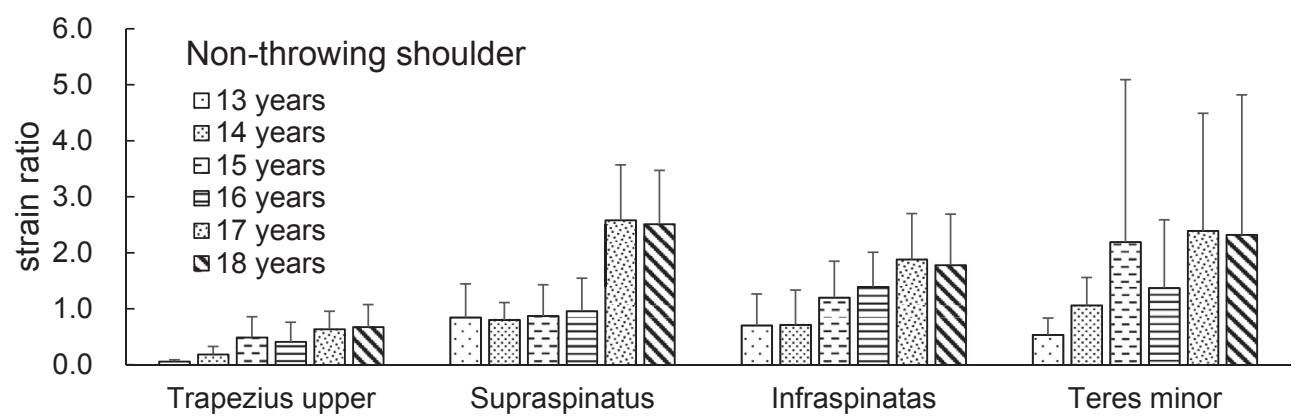

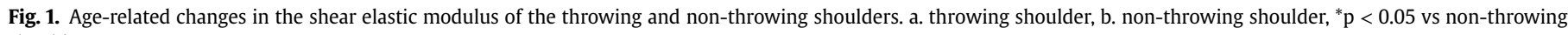
shoulder. Data are mean \pm SD.

pattern from ages 13 to 16 and reached a peak from ages 17 to 18 . When the SEM values of each muscle were compared between the throwing and non-throwing shoulders for each age, the supraspinatus of the throwing shoulder showed significantly higher SEM values in the 18-year-old group. At the time of baseline assessment, $23(19 \%)$ subjects ( $\mathrm{n}=4,5,4,7,2$, and 11 for ages $13,14,15,16,17$, and 18 , respectively) had shoulder joint pain during the throwing motion in baseball practices and games, and there was no significant difference in the prevalence of pain between ages $(\mathrm{p}=0.541)$.

\subsection{Difference between the pain and non-pain groups}

Of 98 subjects who had no shoulder joint pain during the throwing motion at baseline assessment, 21 (21.4\%) developed new shoulder joint pain by 6 months after baseline. Table 2 shows a comparison of the variables between the pain group $(\mathrm{n}=21)$ and the non-pain group $(n=77)$. Compared with the non-pain group, the pain group demonstrated lower body weight, greater internal rotation range of motion in throwing shoulder at baseline, and a significantly lower SEM value of the supraspinatus.

\subsection{Risk factors for shoulder joint pain}

The results of binominal logistic regression analysis, adjusted for age, BMI, playing position, frequency of baseball practice, range of motion of external and internal rotation in throwing shoulder, and muscle strength of external rotation in throwing shoulder, showed that a decrease in the SEM value of the supraspinatus was a risk factor for the development of new pain (odds ratio: 0.056; 95\% confidence interval 0.011-0.299; $\mathrm{p}=0.001$ ) (Table 3 ).

\section{Discussion}

In this study, we used tissue elastography to measure SEM values as an index of the tissue elasticity of muscles around the shoulder joint, with the aim of investigating the relationship between age-related changes in elasticity and the development of shoulder pain during the throwing motion in junior high and high

Table 2

Comparison of groups with and without pain in the throwing shoulder.

\begin{tabular}{|c|c|c|}
\hline & Pain & No-pain \\
\hline & $(\mathrm{n}=21)$ & $(\mathrm{n}=77)$ \\
\hline Age (years) & $15.9 \pm 1.7$ & $15.8 \pm 1.7$ \\
\hline Height $(\mathrm{cm})$ & $162.4 \pm 9.7$ & $166.6 \pm 3.5$ \\
\hline Body weight (kg) & $54.5 \pm 10.1$ & $59.7 \pm 10.3^{*}$ \\
\hline Body mass index $\left(\mathrm{kg} / \mathrm{m}^{2}\right)$ & $20.4 \pm 2.3$ & $21.4 \pm 3.2$ \\
\hline Body fat $(\%)$ & $17.5 \pm 5.5$ & $18.3 \pm 5.4$ \\
\hline Body fat mass (kg) & $9.9 \pm 5.0$ & $11.0 \pm 4.6$ \\
\hline Lean body mass (kg) & $44.2 \pm 6.8$ & $47.2 \pm 2.3$ \\
\hline Muscle mass (kg) & $41.8 \pm 6.4$ & $44.7 \pm 2.2$ \\
\hline \multicolumn{3}{|l|}{ Range of motion of shoulder } \\
\hline Internal rotation in throwing shoulder $\left({ }^{\circ}\right)$ & $78.6 \pm 9.5$ & $71.6 \pm 13.5^{*}$ \\
\hline $\begin{array}{l}\text { Internal rotation in non-throwing } \\
\text { shoulder }\left({ }^{\circ}\right)\end{array}$ & $71.1 \pm 29.0$ & $72.8 \pm 20.9$ \\
\hline External rotation in throwing shoulder $\left(^{\circ}\right)$ & $102.7 \pm 11.6$ & $104.2 \pm 10.2$ \\
\hline $\begin{array}{l}\text { External rotation in non-throwing } \\
\text { shoulder }\left(^{\circ}\right)\end{array}$ & $92.9 \pm 12.5$ & $97.6 \pm 11.2$ \\
\hline \multicolumn{3}{|l|}{ Muscle strength } \\
\hline $\begin{array}{l}\text { External rotation strength in throwing } \\
\text { shoulder }(\mathrm{kgf} / \mathrm{kg})\end{array}$ & $0.11 \pm 0.03$ & $0.10 \pm 0.03$ \\
\hline $\begin{array}{l}\text { External rotation strength in non- } \\
\text { throwing shoulder }(\mathrm{kgf} / \mathrm{kg})\end{array}$ & $0.09 \pm 0.4$ & $0.09 \pm 0.4$ \\
\hline $\begin{array}{l}\text { Knee extension strength in throwing side } \\
(\mathrm{kgf} / \mathrm{kg})\end{array}$ & $0.59 \pm 0.10$ & $0.59 \pm 0.11$ \\
\hline $\begin{array}{l}\text { Knee extension strength in non-throwing } \\
\text { side }(\mathrm{kgf} / \mathrm{kg})\end{array}$ & $0.60 \pm 0.08$ & $0.60 \pm 0.13$ \\
\hline \multicolumn{3}{|l|}{ Elasticity in throwing shoulder } \\
\hline Upper trapezius (strain ratio) & $0.31 \pm 0.4$ & $0.42 \pm 0.7$ \\
\hline Supraspinatus (strain ratio) & $1.03 \pm 0.7$ & $1.66 \pm 1.1^{*}$ \\
\hline Infraspinatus (strain ratio) & $1.28 \pm 0.9$ & $1.43 \pm 1.0$ \\
\hline Teres minor (strain ratio) & $1.68 \pm 1.0$ & $1.72 \pm 1.0$ \\
\hline
\end{tabular}

$* \mathrm{p}<0.05$

Data are mean $\pm \mathrm{SD}$. 
Table 3

Multivariate logistic regression analysis.

\begin{tabular}{|c|c|c|c|c|c|c|c|c|c|c|}
\hline & \multicolumn{5}{|c|}{ Non-Adjusted } & \multicolumn{5}{|c|}{ Adjusted $^{\mathrm{a}}$} \\
\hline & Odds & $95 \% \mathrm{CI}$ & & & p-value & Odds & $96 \% \mathrm{CI}$ & & & p-value \\
\hline Upper trapezius & 1.215 & 0.499 & - & 2.955 & 0.668 & 0.907 & 0.224 & - & 3.681 & 0.892 \\
\hline Supraspinatus & 0.409 & 0.187 & - & 0.891 & 0.024 & 0.056 & 0.011 & - & 0.299 & 0.001 \\
\hline Infraspinatus & 1.215 & 0.663 & - & 2.225 & 0.529 & 0.895 & 0.344 & - & 2.327 & 0.819 \\
\hline Teres minor & 1.120 & 0.675 & - & 1.858 & 0.662 & 0.916 & 0.460 & - & 1.822 & 0.802 \\
\hline
\end{tabular}

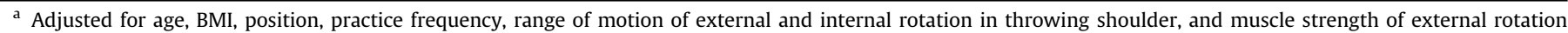
strength in throwing shoulder.

school baseball players. The results of the study revealed that the elasticity of muscle tissues around the throwing shoulder increased with age, and the SEM of the supraspinatus of the throwing shoulder was higher than that of the non-throwing shoulder in the 18 -year-old group. The study also showed that a low SEM value of the supraspinatus of the throwing shoulder was a risk factor for the development of new shoulder pain while throwing.

Previous studies showed that SR measurements of various muscles using the shear elastography function [15-17] were highly reproducible and reliable. However, these studies did not evaluate the reproducibility of SR measurements of muscles around the shoulder joint. In the present study, therefore, we evaluated this reproducibility in seven healthy adult males with no orthopedic disorders (mean age: $32.5 \pm 8.2$ years). For the reproducibility of the elasticity measurement of the target muscles, the ICC $(1,3)$ was $0.786-0.927$ and the CV was $2.2-7.8 \%$. Since it has been reported that an ICC of 0.75 or higher and a CV of less than $12 \%$ indicate good reproducibility [18], the SEM measurements in the present study were considered to have high reproducibility.

The elasticity of the muscle tissues around the shoulder joint tended to increase in a step-like pattern from ages 13 to 16 and reached a peak from ages 17 to 18 . These findings may be due to the fact that muscle elasticity increases with bone growth, since bones and muscles grow at the same time. During the growth spurt period, when height and weight increase most rapidly, bones grow rapidly and many anatomical changes occur throughout the body [19]. During this time, children demonstrate unbalanced growth of bones, muscles and tendons, as well as increased tension of soft tissues such as muscles and tendons [20]. Additionally, the elasticity of numerous muscles, including the iliopsoas muscle, quadriceps muscle, and hamstrings, tends to markedly decrease [19]. Based on these findings, it is considered that the tissue elasticity of the muscles around the shoulder joint also increases from ages 17 to 18 , when the bone mass reaches its peak.

In the present study, however, even though older age was associated with increased muscle elasticity, it was not associated with the number of subjects who experienced shoulder joint pain. Therefore, it is presumed that age-associated increases in muscle stiffness are not directly associated with an increased incidence of shoulder joint injuries. One study reported that an increase in muscle tension due to repeated muscle contraction during the throwing motion was one factor associated with a limited range of shoulder joint motion and reduced muscle elasticity with age in adult baseball players [20]. However, the findings of the present study suggest that additional factors besides repeated throwing are predictive of pain, and that an increase in muscle elasticity in junior high and high school students is associated with growth.

Six months after the baseline assessment, $21.4 \%$ of the subjects in this study presented with new-onset pain around the shoulder joint during the throwing motion. A previous study found that the incidence of throwing-related shoulder injuries in junior high and high school baseball players was 20.4-57.0\% [21], which is consistent with that in the present study. The development of pain within 6 months after the baseline assessment was associated with low SEM values of the supraspinatus of the throwing shoulder, in other words, with low muscle tissue elasticity. While the previous study indicated that an increase in stiffness of posterior muscles, particularly the infraspinatus, was associated with shoulder joint pain, the present study showed that a decrease in elasticity of the supraspinatus was one reason for the development of shoulder joint pain. Another study reported that tightness of the posterior part of the shoulder was a factor associated with throwing-related injuries, and that imbalances in muscle stiffness, particularly between the infraspinatus and supraspinatus, led to shoulder joint pain [22]. Therefore, it is presumed that decreased elasticity of the supraspinatus causes this imbalance in stiffness. Baseball players whose supraspinatus elasticity is increasing more slowly than their bone growth, and those whose muscles have not yet fully matured, may develop pain due to repeated throwing motions.

The limitations of this study were as follows. First, this study included only baseball players, so it is unclear whether its findings on the physical changes during the growth period are representative of the general population. Second, this study evaluated shoulder joint pain but did not assess whether this pain was associated with actual athletic injuries, such as muscle rupture. Although the presence of pain is generally associated with injury, further evaluation is required to confirm a direct relationship between SEM values and athletic injury. In addition, we measured muscle elasticity only with the shoulder in the first position; a stronger relationship might be observed if muscle elasticity were assessed with the shoulder in the painful position. Third, the study did not evaluate whether shoulder pain was affected by involvement in sports other than baseball, lifestyle habits, or non-sporting activities.

In conclusion, the elasticity of muscle tissues on the throwingshoulder side increased with age, but it was not associated with the prevalence of shoulder joint pain. The study suggests that low tissue elasticity of the supraspinatus of the throwing shoulder is a factor associated shoulder pain during throwing. To prevent shoulder joint pain, limiting the number of pitches and sufficient care may be required in school-age baseball players whose supraspinatus tissue elasticity is not progressing at the same rate as bone growth. Since the use of shear wave elastography to measure the SEM of muscles around the shoulder joint allows for objective evaluation of muscle elasticity, it may be used to prevent athletic injuries.

\section{Conflict of interest}

None.

\section{References}

[1] Kubo K, Morimoto M, Komuro T, Yata H, Tsunoda N, Kanehisa H, Fukunaga T. Effects of plyometric and weight training on muscle-tendon complex and jump performance. Med Sci Sports Exerc 2007 Oct;39(10):1801-10. 
[2] Murayama M, Watanabe K, Kato R, Uchiyama T, Yoneda T. Association of muscle hardness with muscle tension dynamics: a physiological property. Eur J Appl Physiol 2012 Jan;112(1):105-12.

[3] Horikawa M, Ebihara S, Sakai F, Akiyama M. Non-invasive measurement method for hardness in muscular tissues. Med Biol Eng Comput 1993 Nov;31(6):623-7.

[4] Murayama M, Nosaka K, Yoneda T, Minamitani K. Changes in hardness of the human elbow flexor muscles after eccentric exercise. Eur J Appl Physiol 2000 Aug;82(5-6):361-7.

[5] Olsen 2nd2nd, Fleisig GS, Dun S, Loftice J, Andrews JR. Risk factors for shoulder and elbow injuries in adolescent baseball pitchers. Am J Sports Med 2006 Jun;34(6):905-12.

[6] Matsuura T, Suzue N, Iwame T, Arisawa K, Fukuta S, Sairyo K. Epidemiology of shoulder and elbow pain in youth baseball players. Phys Sportsmed 2016;44(2):97-100.

[7] Takagishi K, Matsuura T, Masatomi T, Chosa E, Tajika T, Iwama T, Watanabe M, Otani T, Inagaki K, Ikegami H, Aoki M, Okuwaki T, Kameyama Y, Akira M, Kaneoka K, Sakamoto M, Beppu M. Shoulder and elbow pain in junior high school baseball players: results of a nationwide survey. J Orthop Sci 2019 Jul;24(4):708-14.

[8] Koo Terry K, Guo Jing-Yi, Cohen Jerry H, Parker KJ. Relationship between shear elastic modulus and passive muscle force: an ex-vivo study. J Biomech 2013 Aug;46(12):2053-9.

[9] Dhyani M, Grajo JR, Bhan AK, Corey K, Chung R, Samir AE. Validation of shear wave elastography cutoff values on the supersonic aixplorer for practical clinical use in liver fibrosis staging. Ultrasound Med Biol 2017 Jun;43(6): 1125-33.

[10] Maïsetti Olivier, Hug François, Killian Bouillard, Nordez A. Characterization of passive elastic properties of the human medial gastrocnemius muscle belly using supersonic shear imaging. J Biomech 2012 Apr;45(6):978-84.

[11] Muraki T, Ishikawa H, Morise S, Yamamoto N, Sano H, Itoi E, Izumi S. Ultrasound elastography-based assessment of the elasticity of the supraspinatus muscle and tendon during muscle contraction. J Shoulder Elb Surg 2015 Jan;24(1):120-6.
[12] Y1 Yoshitake, Takai Y, Kanehisa H, Shinohara M. Muscle shear modulus measured with ultrasound shear-wave elastography across a wide range of contraction intensity. Muscle Nerve 2014 Jul;50(1):103-13.

[13] Nordez A1, Hug F. Muscle shear elastic modulus measured using supersonic shear imaging is highly related to muscle activity level. J Appl Physiol 2010 May;108(5):1389-94.

[14] Eby SF, Song P, Chen S, Chen Q Greenleaf JF, An KN. Validation of shear wave elastography in skeletal muscle. J Biomech 2013 Sep 27;46(14):2381-7.

[15] Lacourpaille L, Hug F, Bouillard K, Hogrel JY, Nordez A. Supersonic shear imaging provides a reliable measurement of resting muscle shear elastic modulus. IOP Science 2012 Mar;33(3):N19-28.

[16] Umegaki H, Ikezoe T, Nakamura M, Nishishita S, Kobayashi T, Fujita K, Tanaka $\mathrm{H}$, Ichihashi $\mathrm{N}$. The effect of hip rotation on shear elastic modulus of the medial and lateral hamstrings during stretching. Man Ther 2015 Feb;20(1):134-7.

[17] Leong HT, Ng GY, Leung VY, Fu SN. Quantitative estimation of muscle shea elastic modulus of the upper trapezius with supersonic shear imaging during arm positioning. PLoS One 2013 Jun;8(6):e67199.

[18] Nussbaumer S, Leunig M, Glatthorn JF, Stauffacher S, Gerber H, Maffiuletti NA Validity and test-retest reliability of manual goniometers for measuring passive hip range of motion in femoroacetabular impingement patients. BMC Musculoskelet Disord 2010 Aug 31;(11):194.

[19] Akagi R, Yamashita Y, Ueyasu Y. Age-related differences in muscle shea Moduli in the lower extremity. Ultrasound Med Biol 2015 Nov;41(11): 2906-12.

[20] Chou PP, Chou YL, Wang YS, Wang RT, Lin HT. Effects of glenohumeral interna rotation deficit on baseball pitching among pitchers of different ages. J Shoulder Elb Surg 2018 Dec 11;27(4):599-605.

[21] Harada M, Takahara M, Mura N, Sasaki J, Ito T, Ogino T. Risk factors for elbow injuries among young baseball players. J Shoulder Elb Surg 2010 Jun;19(4): $502-7$.

[22] Wilk Kevin E, Macrina Leonard C, Fleisig GS. Correlation of glenohumeral internal rotation deficit and Total rotational motion to shoulder injuries in Professional baseball pitchers. Am J Sports Med 2011 Feb;39(2). 329-325. 